\title{
Um olhar pastoral sobre o luto e a violência
}

\author{
A pastoral view on the grief and the violence
}

\section{Blanches de Paula*}

[a] Universidade Metodista de São Paulo (UMESP), São Bernardo do Campo, SP, Brasil

\section{Resumo}

O presente artigo tem por finalidade lançar um olhar teológico-pastoral sobre a relação entre violência e luto. Partimos do pressuposto de que, com os crescentes índices de violência, há uma ampliação do processo de enlutamento na sociedade. Diante desse cenário, o objetivo geral desta pesquisa é correlacionar o tema da violência com o tema do luto, bem como apontar caminhos para pastorais que abordem essa temática, uma vez que consideramos o cuidado pastoral como contribuinte na elaboração dos lutos desencadeados por violência.

Palavras-chave: Violência. Luto. Cuidado Pastoral.

*BP: Doutora em Ciências da Religião, e-mail: blanches.paula@metodista.br 


\section{Abstract}

The present article aims to launch a theological-pastoral view on the relationship between violence and grief. We start from the assumption that with the increasing rates of violence, there is an expansion of the process of grieving in society. In view of this scenario, the general objective of this research is to correlate the theme of violence with the theme of grief, as well as to point out pastoral paths that approach this theme, since we consider pastoral care as a contributor in the elaboration of grievances triggered by violence.

Keywords: Violence. Grief. Pastoral. Care.

\section{Introdução}

Quando abordamos o tema da violência e do luto, geralmente surgem conexões que emergem em nossos pensamentos que envolvem questões relacionadas a perdas e injustiças. Numa sociedade imediatista, que tem por característica a perda da relevância do tempo das vivências relacionais, o processo de morrer é envolvido com a banalização da dor. A coisificação do processo de morrer, que acontece em mortes naturais, torna-se uma petrificação das relações, quando a morte advém de um ato violento. Percebe-se, diante desse contexto, que a perda dos sentidos de ser humano, tenta minar a esperança.

O presente artigo tem como objetivo, oferecer caminhos introdutórios da relação entre violência e luto, relação esta que é possível quando olhamos uma sociedade enlutada que precisa ampliar os espaços de escuta terapêutica do tratamento do agressor/a e o agredido/a e, também, rever constantemente os sistemas de reabilitação de quem sofreu violência em nossa realidade brasileira ${ }^{1}$. Ademais, a relação entre violência e luto é um tema que ainda precisa ser ampliado e aprofundado na reflexão teológico-pastoral.

1 Destacamos que o projeto (PLS 9/2016) que inclui o cuidado com o agressor num centro de reabilitação, da Comissão de Direitos Humanos (CDH), foi aprovado pela Câmara dos Deputados e pelo Senado Federal, em 12 de abril de 2016. 
Ao tratarmos, mesmo que de forma introdutória, a relação entre luto e violência, propomos um diálogo entre morte, perda de sentido da vida e esperança. Para tanto, contamos nesta reflexão com os autores Alves (2014), Bauman (2007), Kovács (2008), Koury (2003), Tutu (2016). Num primeiro momento, o artigo versa sobre a relação entre o luto escondido e a violência explícita. Em seguida, sobre o escancaramento do luto e a negação da violência. E, por fim, reflete sobre algumas das dimensões teológicopastorais para a construção de uma pastoral do luto com dignidade.

\section{Luto abscôndito e violência escancarada}

O luto, como processo desencadeado por perdas imbuídas de vínculo afetivo, é uma pauta indispensável nos estudos sobre a violência. Especialmente quando constatamos que a violência se tornou parte de um leque de expressões que foram banalizadas em seus conceitos. Houaiss (2004) define violência como emprego de força física, dano e injustiça. Geralmente essas expressões estão vinculadas à violência contra a mulher, a criança, o/a idoso/a, o/a jovem, o/a negro/a em que, por vezes, o processo de luto fica oculto. Nesse contexto, a violência pode desencadear um processo traumático nas perdas, nos sentidos de vida e no senso de justiça.

Para o Relatório Mundial Violência-Saúde da Organização Mundial de Saúde (2002), o conceito de violência envolve o poder e seu uso no campo social.

A Organização Mundial da Saúde define violência, como: O uso intencional da força física ou do poder, real ou em ameaça, contra si próprio, contra outra pessoa, ou contra um grupo ou uma comunidade, que resulte ou tenha grande possibilidade de resultar em lesão, morte, dano psicológico, deficiência de desenvolvimento ou privação. A definição utilizada pela Organização Mundial da Saúde associa intencionalidade com a prática do ato propriamente dito, independentemente do resultado produzido (KRUG, 2002, p. 5).

Além disso, a conceituação de violência, pela Organização Mundial da Saúde (OMS) de 2002, inclui as consequências do uso da força nas pessoas, especialmente na sua dimensão psíquica e relacional. Ademais, vale lembrar 
que o Relatório faz uma conexão entre a violência e a saúde, como premissas indispensáveis para uma sociedade que defende a justiça relacional.

Ao visitar a teologia bíblica, encontramos uma relação próxima entre violência e justiça em que o princípio ético transcende as definições acima.

Na língua bíblica, o termo justiça é chamado sedaqah. [...] A partir do conceito de sedeq ou sedaqah, no AT, justiça assume o sentido de salvação, libertação para todos e todas [...] A justiça a que Jesus se refere não é para criar tribunais de julgamento, mas tão somente para salvar e criar condições de vida digna para homens e mulheres (SIQUEIRA, 2005, p. 68).

A partir dessa definição, percebemos que a prática da justiça envolve educação para a dignidade e para os direitos e deveres de convivência. Esses princípios de convivência são indispensáveis para lidarmos com a realidade da violência e o cultivo de espaços de luto sadio. Ou seja, a prática da justiça, na relação entre luto e violência, não é somente a defesa do direito à vida, mas também ao de morrer com dignidade. Morrer com dignidade é dar continuidade aos valores da vida justa para aquele/as que trazem à memória da perda de quem partiu. Com o processo de vulgarização do luto, desencadeado por atos de violência, perde-se o direito ao lamento na sociedade. O lamento, dentro do contexto bíblico é indispensável para ressignificar os sentidos de viver e a prática da justiça. Talvez seja por isso que, na Bíblia, o ato de lamentar era um ato comunitário.

O retrato da violência continua em nossa realidade atual e clama por um lamento que gere justiça social. Podemos verificar essa realidade no Atlas da Violência de $2017^{2}$. Esse documento registra que a violência ainda se prolifera, especialmente entre as mulheres e de maneira particular entre negros/as.

O perfil típico das vítimas fatais permanece o mesmo: homens, jovens, negros e com baixa escolaridade. Contudo, nos chama a atenção o fato de que, na última década, o viés de violência contra jovens e negros tenha aumentado ainda mais (CERQUEIRA, 2017, p. 55).

2 O Atlas da Violência é um documento que oferece um panorama sobre a situação da violência no Brasil. Esse mapeamento da violência tem contribuído para ações preventivas em prol da paz relacional na sociedade brasileira, além de detectar os pontos nevrálgicos da violência na atualidade, com destaque para a juventude negra. 
A cultura da violência e a vulnerabilidade, na defesa dos direitos humanos, tem transformado a vida das pessoas, com o perfil descrito acima, em alvos fáceis de agressividade social. Temas como gênero e racismo se misturam no quadro da violência e tornam o luto cada vez mais escondido e, talvez para muitos, desnecessário.

Ainda que, em termos de letalidade violenta, as mulheres sejam menos afligidas, este número representa uma pequena ponta do iceberg das centenas de milhares de violências (físicas, psicológicas e materiais) que afligem a população feminina, que são motivadas por uma cultura patriarcal e que passam invisíveis aos olhos da sociedade. No entanto, as diferenças raciais apareceram mais uma vez misturadas à questão de gênero. Enquanto a taxa de homicídios de mulheres não negras diminuiu 7,4\%, entre 2005 e 2015, o indicador equivalente para as mulheres negras aumentou 22,0\% (CERQUEIRA, 2017, p. 56).

Diante desse quadro, podemos afirmar que há falta de espanto e da busca por uma justiça mais comunitária e solidária que possa lidar com a violência. A chamada "justiça” com "as próprias mãos" ainda é muito presente em solo brasileiro. Parece que há descrédito pela necessidade do luto, como busca pela justiça e a ética nas relações sociais. Essa atitude encobre dores, perdas e afasta possibilidades de reconciliação com a vida. $\mathrm{O}$ espanto diante da violência é raro, por lado é importante afirmar que pesquisas, estudos e grupos que defendem a não violência cresceram nos últimos anos ${ }^{3}$.

Kovács (2008), em sua análise sobre os tipos de morte que existem na história humana, contribuiu para ilustrar como a morte regada de violência é encarada com naturalidade.

Morte escancarada é o nome que atribuo à morte que invade, ocupa espaço, penetra na vida das pessoas a qualquer hora. Pela sua característica de penetração dificulta a proteção e controle de suas consequências: as pessoas ficam expostas e sem defesas. Ela não é aberta à comunicação como a morte re-humanizada, na qual se vê um processo gradual e voluntário regido pelo sujeito. Ou seja, a morte escancarada é brusca, repentina, invasiva e involuntária.

3 Entidades como o Núcleo de Estudos da Violência da Universidade de São Paulo são um exemplo de interesses de estudos da Violência. Disponível em: <http://nevusp.org/>. Acesso em: 04 ago. 2017. 
Exemplifico a morte escancarada com duas situações: a morte violenta das ruas, os acidentes e os homicídios; a morte veiculada pelos órgãos de comunicação, mais especificamente pela TV (KOVÁCS, 2008, p. 141).

Tomamos emprestado a expressão "escancarada" para designar a violência no sentido de seu teor invasivo, desrespeitoso e desumanizado. É importante salientar que o escancaramento da morte violenta não minimiza o anestesiamento dos sentimentos e a sensação de impotência diante de ações violentas que envolvem nosso cotidiano. Esse anestesiamento dos sentimentos é a precarização da empatia e da solidariedade diante da dor de outrem. Bauman (2007) nos lembra que a relação com a mídia pode ampliar o anestesiamento frente à violência, pelas exigências cada vez mais cruéis das imagens transmitidas para as pessoas.

Uma das consequências disso é o grande número e a monotonia das imagens em causa poderem produzir um efeito de desgaste: dado 'o cansaço do espectador', terão de ser cada vez mais violentas, chocantes ou 'inventivas' a fim de suscitarem qualquer tipo de emoção ou para simplesmente chamarem sobre si as atenções. O nível 'familiar' da violência, abaixo do qual a crueldade das ações cruéis escapa à atenção, sobe constantemente (BAUMAN, 2007, p. 156).

Ademais, a violência "escancarada" inclui noções de justiça, tanto no âmbito individual, como coletivo. Nessa dimensão do conceito de violência, adentramos num terreno repleto de definições que se misturam com a vingança e sua toxicidade nas relações humanas. Obviamente, não há como discorrer sobre a justiça se não reivindicarmos os princípios éticos que a norteiam. Esses princípios éticos envolvem a disposição de rever atitudes a partir das nossas decisões, sejam as mais simples até as mais complexas. Essas decisões estão relacionadas aos direitos universais da convivência humana no uso do poder nas relações. Nesse quesito, a exposição da violência em nosso cotidiano é um convite constante para que possamos revisitar nossa sensibilidade, empatia, solidariedade, compaixão e justiça. 


\section{Luto escancarado e a negação da violência}

Ao falar de luto escancarado, referimo-nos à dor da perda que não cessa, mas que é invisibilizada nas relações sociais. Quando abordamos o luto escancarado, evocamos a dor da perda exposta, sem proteção, sem espaço de cuidado e sem elaboração. É o luto que não cessa. Esse luto incessante torna nossa sociedade mais vulnerável à cultura da violência. A violência torna-se tão natural que a defesa da vida e da justiça recebe certo estranhamento social. No caso brasileiro, parece que o luto escancarado está relacionado também com o ressentimento.

O ressentimento na sociedade brasileira está enraizado em nossa dificuldade em nos reconhecermos como agentes da vida social, sujeitos de nossa história, responsáveis coletivamente pela resolução dos problemas que nos afligem. Suas raízes remontam à tradição paternalista e cordial de mando, que mantém os subordinados em uma relação de dependência filial e servil em relação às autoridades - políticas ou patronais - na expectativa de ver reconhecidos e premiados o bom comportamento e a docilidade de classe (KEHL, 2005, p. 172).

Diante disso, o escancaramento do luto, sem espaços de cuidado, escuta, de aprendizado mútuo, de enfrentamento das crises e acolhimento social, pode desencadear uma pandemia de danos físicos, sociais e psíquicos na população e se agigantar ainda mais a cada negação da violência. Kovács (2008) defende a criação de serviços de apoio psicológico e intervenções nas crises diante de perdas por violência. E poderíamos acrescentar a isso o serviço de consolo espiritual e religioso. Esse consolo espiritual, somase ao cuidado concedido por vocações de outras áreas do conhecimento que oferecem suporte no processo do luto como: a psicologia, medicina, educação, assistência social, direito, dentre outras.

Numa sociedade em que o império dos direitos do capital sobrepuja a dignidade da vida das pessoas empobrecidas, há uma linha tênue entre violência e justiça, como já mencionado anteriormente. Nesse sentido, quase se tornam sinônimas. 
A violência e a ausência de justiça reduzem o indivíduo à sua condição mais ordinária, abandonado ao desespero de sobreviver à própria dor, quase sem suportá-la, alimenta o desejo de vingança e justiça, o que aumenta ainda mais a violência urbana. A ação violenta passa a ser um dispositivo a ser acionado a qualquer momento, como patrimônio pessoal, diante de uma justiça pública e que tarda e falha. Ao mesmo tempo, a violência é alimentada pelos poderes econômico, jurídico e policial (ALVES, 2014, p. 135).

A relação entre luto e justiça também é relevante, especialmente quando olhamos o processo do luto como um direito à vida e à vivência da dor com dignidade. A negação da violência coloca em destaque uma fase do luto que, se não for bem elaborada, pode proliferar novos atos violentos. Estamos falando do estágio da raiva ${ }^{4}$.

A raiva é uma espécie de explosão de dor que pode ter várias facetas e momentos. Facetas porque a raiva pode ter vários alvos. Momentos, porque a raiva pode 'aparecer' em situações esperadas e inesperadas. Na raiva, a exposição da pessoa é grande e por vezes pode não haver um controle do sentimento que pode se transformar em agressividade (PAULA, 2011, p. 63).

O que queremos dizer é que a pessoa enlutada tem direito de expressar sua raiva, isso é parte da elaboração do luto. A raiva não é somente um sentimento, mas pode ser também um pedido de socorro. Quando a pessoa não tem um espaço de cuidado para essa elaboração e não se consegue os caminhos adequados e ágeis para a prática da justiça, a oração e o pedido de socorro podem tornar-se um grito em busca da justiça. Lembramos da história de Marta e Maria, por ocasião da morte do seu irmão Lázaro (Lc 11,21 e 32), ao expressar a ausência de Jesus num momento tão difícil na família: "Senhor, se estiveras aqui, não teria morrido meu irmão".

Porém, o pedido de socorro embutido na raiva também pode tornar-se um grito por vingança.

4 Segundo Kubler-Ross existem cinco fases do luto: negação, raiva, barganha, depressão e aceitação. Indicamos algumas obras do autor que podem ajudar no aprofundamento do tema em análise: KUBLERROSS, E. Sobre a morte e o morrer. 0 que a morte pode ensinar aos médicos, enfermeiras, padres e suas famílias. Trad. Thereza Kipnis. São Paulo: EDUSP\EDHART, 1977. A Roda da Vida: Memória do Viver e do Morrer. São Paulo: Sextante, 1998. A morte: um amanhecer. São Paulo: Pensamento-Cultrix, 1999. 0 Túnel e a Luz: reflexões essenciais sobre a vida e a morte. Campinas: Verus, 2003. 
Assassinatos e homicídios - neste caso, a morte é intencional, resultado da ação humana, provoca muita raiva e desejo de vingança e mantém o foco na perda. Os familiares são cruelmente abandonados ao luto covarde, à fúria e ao senso de violação que acompanham o ato repugnante do assassino. $\mathrm{O}$ lento sistema legal ao atrasar o julgamento, atrasa também o processo de luto, reabrindo a ferida a cada julgamento e apelação. Geralmente a sentença parece banal frente à magnitude da perda, evocando intensa raiva $\mathrm{e}$ minando a confiança no sistema policial e legal do qual se espera proteção, o que provoca mais culpa por não defender o morto (ALVES, 2014, p. 133).

Nesse viés de pensamento, não podemos nos esquecer de que algumas mídias, ao privilegiar o ganho econômico, sustentam uma escola de violência que não tem nenhuma conotação educativa. Vale a pena lembrar que a fascinação por sangue, cenas violentas, não aparecem somente em noticiários, mas são protagonistas de algumas culturas cinematográficas.

Está presente nos noticiários, programas de auditório, novelas e filmes. É a morte que invade os lares a qualquer hora, assistida por todos, inclusive crianças. O que a faz escancarada são as cenas e imagens mostradas, chocantes, repetidas à exaustão e o texto que as acompanha, principalmente quando há coleta de depoimentos na hora mesmo do acontecimento - texto, na maioria das vezes, superficial, sem espaço para reflexão (KOVÁCS, 2008, p. 142).

O consumismo da violência, preconizado pelas mídias, é ingrediente indispensável para uma naturalidade da agressão social em que todos nós podemos ser plateia ou atores. O luto escancarado evidencia não só a negação da violência, mas também do próprio direito ao enlutamento. De certa forma, parece que enlutar-se é vergonhoso, um tabu. Aliado a isso, destacamos os mecanismos de medo que envolvem a relação entre luto e violência. E esse medo, por sua vez, pode gerar sofrimento ${ }^{5}$.

5 Mauro Guilherme Pinheiro Koury coordena o GREM - Grupo de Pesquisa em Antropologia e Sociologia das Emoções que tem realizado pesquisas relevantes sobre o luto e o sofrimento no contexto brasileiro, na ótica da Sociologia e da Antropologia. É professor na Universidade Federal da Paraíba, editor da Revista Brasileira de Sociologia da Emoção. Dentre seus livros, destacamos: KOURY, M. G. P. (org.). Imagem e memória: ensaios em antropologia visual. Rio de Janeiro: Garamond, 2001. 
Socialmente, parece, a tendência da nova sensibilidade emergente no Brasil de negar a morte e o sofrimento pela morte na esfera social vem sendo feita através de uma ênfase na morte como código norteador e ameaçador atrás das regras sociais. Configura-se no adotar o ponto de vista da resignação social como constructo possível do ser moral na modernidade. Resignação do eu constrangido na intimidade, para dar lugar ao indivíduo indiferente e fragmentado no social (KOURY, 2003 p. 35).

A negação do luto, gerado pela violência, pode atingir o tecido social ao fragmentá-lo e enfraquecer os espaços de solidariedade e retomada da vida em comunidade. Diante dessa realidade, destacamos as esferas sociais mais atingidas pela negação do sofrimento: mulheres, negros/as, crianças, idosas/ os, pobres, doentes, homossexuais. A imagem deste outro/a que está diante de nós, pode nos deixar sem ar pela dor e sofrimento que não suportamos. Ou ainda, na surpresa de que essas pessoas, mesmo em meio ao sofrimento, vivem melhor do que a mesquinhez da aparência e do deus capital.

A invisibilidade do/a outro/a que sofre violência, atesta a cegueira e onipotência de algumas pessoas e pode violar as relações que, de humanas, tornam-se plásticas, mecânicas. O humano desaparece e o império da coisificação urge no desvalor do/a outro/a que também nos constitui. A morte violenta evoca sofrimento não somente pelo luto, mas também pelo sequestro da dignidade no morrer. $\mathrm{O}$ sofrimento pode ser alargado ainda mais diante da morosidade da justiça, da justiça não praticada, da culpa e da falta de espaços de cuidado diante das perdas na sociedade.

\section{Por uma pastoral do luto com dignidade}

Uma pastoral do luto envolve um olhar amplo sobre a realidade que vivemos, mas também se inspira no Evangelho, como possibilidade de desenhar ações que elevem o humano e sua dignidade diante das perdas. Os textos do Evangelho trazem sementes de esperança e sabedoria que podem oferecer uma bússola na construção de caminhos para pastorais que envolvam o luto diante da violência.

Antes de indicar o texto que norteará essa pastoral é importante lembrar que a elaboração do luto é o processo que a pessoa, família, grupo enlutado/a 
atravessa, até ter condições de saúde necessárias para a continuidade da vida em meio à ausência da pessoa, do trabalho, do/a cônjuge, dentre outras perdas. A escolha pelos Evangelhos de Mateus e João justifica-se porque ambos abordam, de forma mais explícita, o tema da justiça e do discurso de despedida de Jesus e a vinda do Consolador, o Espírito Santo. Antes, porém de adentramos, mesmo que brevemente nos Evangelhos, destacamos que o tema da Campanha da Fraternidade da Igreja Católica trata justamente desse tema em 2018:

Para o ano de 2018, foi escolhido o tema "Fraternidade e superação da violência" e o lema: "vós sois todos irmãos" (Mt 23,8), com o objetivo geral de construir a fraternidade, promovendo a cultura da paz, da reconciliação e da justiça, à luz da palavra de Deus, como caminho de superação da violência. O tema da CF-2018 pretende advertir que a violência nunca constitui uma resposta justa. A Igreja proclama, com a convicção de sua fé em Cristo e com a consciência de sua missão, que a violência é um mal, é inaceitável como solução para os problemas e não é digna do ser humano (SILVA, 2018, p. 3).

O Evangelho de Mateus propõe abraçar as pessoas para além da fronteira do antigo Israel e está endereçado à uma comunidade judaicocristã. Um dos temas fundamentais do Evangelho é a justiça como expressão de misericórdia, reconciliação, salvação e responsabilidade pela Vida. Dentre vários textos, o de Mt 5,21-26 pode ser um prefácio a um cuidado pastoral diante do luto e da violência.

${ }^{21}$ Ouvistes que foi dito aos antigos: Não matarás; e quem matar estará sujeito a julgamento. ${ }^{22} \mathrm{Eu}$, porém, vos digo que todo aquele que [sem motivo], se irar contra seu irmão, estará sujeito a julgamento; e quem proferir um insulto a seu irmão estará sujeito a julgamento do tribunal; e quem lhe chamar: "Tolo", estará sujeito ao inferno de fogo. ${ }^{23}$ Portanto, se trouxeres a tua oferta ao altar, e aí te lembrares de que teu irmão tem alguma coisa contra ti ${ }^{24}$ deixa ali diante do altar a tua oferta, e vai primeiro reconciliar-te com teu irmão e, então, voltando, faze a tua oferta. ${ }^{25}$ Entra em acordo sem demora com o teu adversário, enquanto estás com ele no caminho, para que o adversário não te entregue ao juiz, o juiz, ao oficial de justiça, e sejas recolhido à prisão. ${ }^{26} \mathrm{Em}$ verdade te digo que não sairás dali enquanto não pagares o último centavo. 
A justiça de Deus tem um teor relacional. O texto de Mt 5,21-26 é a continuidade de uma premissa colocada no versículo 20: se a vossa justiça não exceder. É uma conversa sobre lei e justiça! O Reino dos fariseus e escribas, fervorosos seguidores da lei de Moisés, precisava ser transcendido por meio da radicalidade do agir. Esse texto fala a respeito de nossas atitudes com o/a outro/a e é uma aula para quem escolheu ser guiado/a pelos princípios do Reino da justiça, também conhecido como Reino dos Céus e, em outros evangelhos, Reino de Deus.

A justiça é o alicerce para a vivência do Reino de Deus. A justiça é a base para a relação com Deus, com os outros e conosco mesmos/as. Não é por acaso que, no Sermão da Montanha, há várias ênfases sobre esse fundamento. Uma delas está no conhecido versículo: "Buscai o Reino e a sua Justiça e todas as coisas vos serão acrescentadas" (Mt 6,33).

Outro ponto que merece destaque no texto e que se vincula ao tema da violência e do luto é o desprezo, comparado com uma morte relacional. Nesse texto, encontramos o sentido de matar alguém como prática da justiça humana. Jesus reafirma que a intenção de matar quem nos feriu está presente no ser humano. Ou seja, matar não está somente na eliminação da pessoa. O abandono, a rejeição, o desprezo do/a outro/a tem o mesmo peso de "morte" diante de Deus. Quanto maior o número de invisíveis sociais, maior a prática da injustiça numa sociedade. Quando colocamos alguém no mais desprezível patamar de nossa vida, estamos o/a matando!

Destacamos, assim, as atitudes de reconciliação como ensinamento que nos vocaciona a lidar com a violência e o luto não elaborado. Celebrar a vida é oferecer e cultivar a misericórdia e a justiça entre as pessoas. $\mathrm{O}$ perdão é um dos caminhos para a reconciliação. Com atitudes de perdão, reafirmamos que a comunidade tem capacidade de rever sua trajetória relacional sem se desintegrar. Desmond Tutu (2016), que optou pela educação pela paz, nos alerta sobre isso.

A única maneira de encontrar a liberdade e a paz é perdoar. Até conseguirmos perdoar, permanecemos trancados na nossa dor e barrados da possibilidade de encontrar a superação e a liberdade, barrados da possibilidade de ter paz (TUTU, 2016, p. 24). 
Em meio a tantos sistemas de convivência que proliferam a injustiça, o ato de perdoar pode ser um grito de liberdade que não abre mão da justiça, ao contrário, a reafirma. Ao perdoar não proliferamos a violência, mas abrimos possibilidade de criação de sistemas mais justos também para os/as vitimizadores/as.

Outro texto da teologia bíblica que destacamos é do Evangelho de João capítulo 14,14-18 que diz:

${ }^{16}$ E eu rogarei ao Pai, e ele vos dará outro Consolador, a fim de que esteja para sempre convosco ${ }^{17} \mathrm{o}$ Espírito da verdade, que o mundo não pode receber, porque não o vê, nem o conhece, vós o conheceis, porque ele habita convosco e estará em vós. ${ }^{18}$ Não vos deixarei órfãos, voltarei para vós outros.

Deus Pai e Filho se faz um em nós, por meio do Espírito da Verdade. Deus oferece Seu amor que, sopra onde quer e nos capacita para vivenciar situações festivas e dolorosas com dignidade e paz. O Espírito, o Consolador, a presença de Deus entre nós, faz com que o amor de Deus cresça entre as pessoas, as envolva no milagre das relações que podem anunciar o Reino de Deus por meio de atitudes. O Espírito Santo Consolador oferece-nos a capacidade de estar em silêncio em meio a dor do outro, a alegrar com os que se alegram e a chorar com os que choram. Também nos capacita a sair de nós mesmos/as em direção ao outro que está vulnerável, à margem da Vida e até de si mesmo. Além disso, inspira às pessoas busca por justiça e paz de forma comunitária. Calvani (1996) defende uma pneumatologia, cujo poder do Espírito Santo esteja aliado a mudanças e transformações no ser humano e na sociedade:

Uma pneumatologia sadia e coerente com os princípios do Evangelho não pode vislumbrar a violência (física ou cultural) como estratégia ou sinal de espiritualidade. Longe de ser demonstração de poder genuíno, a violência revela exatamente a carência de poder. [...]. Necessitamos de uma teologia que revele o Espírito como transformador e não como destruidor ou aniquilador. Em termos bíblicos, a atividade própria do Espírito é transformar, nunca destruir (CALVANI, 1996, p. 63).

Naquela ocasião em que o Império Romano oprimia o povo, o anúncio do Espírito Consolador, por Cristo, recordava o ministério profético em que consolar era anunciar a justiça. Na comunidade guiada 
pelo Espírito consolador, não há orfandade, pois nos tornamos uma família que oferece o cuidado do Pai, do Filho e do Espírito, para prosseguimos em nossa jornada, seja em meio às perdas, seja em meio às alegrias.

Com essas duas sabedorias advindas do Evangelho: justiça e consolo, podemos nutrir os alicerces de uma Pastoral do Luto com dignidade que é encontrada em toda a Escritura e, também, na sistematização da Teologia no decorrer dos tempos. Através do aconselhamento pastoral, as pessoas enlutadas podem compreender e aceitar melhor a dor da perda de um ente querido. Tal vivência não deixa de ser um processo de aprendizagem e de amadurecimento. A partir daí é que o enlutado descobrirá novos conceitos e valores. Assim, as perdas acompanham o ser humano em todo o seu processo de crescimento, desenvolvimento e maturidade.

\section{Considerações finais}

Dialogar sobre violência e luto requer vários olhares sobre a realidade humana em sociedade. É fato que a geografia da violência, da situação social, econômica e política, pode fazer com que o medo seja maior que as possibilidades para a construção de caminhos de paz. Pensar numa Teologia da Reconciliação como um caminho que pode ser construído, quando lidamos com o luto gerado pela violência, é um sinal de esperança. Esperança porque reconciliação não significa que haverá uma romantização do processo de perdão, mas que é possível continuar a vida sem ter como base uma violência recebida ou praticada.

Junto à reconciliação, adentramos na atitude de perdoar, que, além de ser libertadora, é um convite à transformação da pedagogia do sentimento da vingança para a pedagogia do perdão e do recomeço. Além disso, o campo teológico pode contribuir com o apaziguamento diante de culturas do ressentimento. A teologia da reconciliação não se volta, portanto, só para o indivíduo, mas para a comunidade. É uma voz profética que denuncia a cultura da violência e anuncia e cultiva uma cultura de solidariedade e recomeços!

Finalmente, para a semeadura da justiça é indispensável uma educação que esteja presente não somente nas escolas, igrejas, instituições, 
mas que envolva as famílias. Essas também necessitam vivenciar espaços de reconciliação diante das perdas e violências que enfrentam.

\section{Referências}

ALVES, E. G. R. A morte matada: luto por violências. In: Tratado Brasileiro Sobre Perdas e Luto. SANTOS, F. S.; SCHIEMANN, A. L.; SOLANO, J. P. C. (org.). São Paulo: Atheneu Editora, p.131-136, 2014.

BAUMAN, Z. A Vida fragmentada. Trad. Miguel Serras Pereira. 2. ed. Lisboa: Relógio D’Água Editores Zahar, 2007. 311 p.

BÍBLIA de Estudo Almeida. Trad. João Ferreira de Almeida. Barueri: Sociedade Bíblica do Brasil, 2006.

CALVANI, C. E. B. Violência e Cultura: pistas para uma leitura teológica da cultura religiosa. In: CALVANI, C. E. B. Violência e cultura. São Bernardo do Campo: EDIMS, 1996. p. 37-65.

CERQUEIRA, D.; et al. Atlas da Violência. Ipea; Fórum Brasileiro de Segurança Pública (FBSP). Rio de Janeiro, 2017. Disponível em: <http://www.ipea.gov.br/ atlasviolencia/arquivos/downloads/8623-170602atlasdaviolencia2017.pdf > Acesso em: 20 dez. 2017.

HOUAISS, A.; et al. Dicionário Houaiss da língua portuguesa. Rio de Janeiro: Objetiva, 2004. 2922 p.

KEHL, M. R. O ressentimento camuflado da Sociedade brasileira. Novos Estudos, São Paulo, n. 71, p. 163-180, mar. 2005.

KOURY, M. G. P. Sociologia da emoção: o Brasil urbano sob a ótica do luto. Petrópolis: Vozes, 2003. 215 p.

KUBLER. R. E. Sobre a morte e o morrer. O que a morte pode ensinar aos médicos, enfermeiras, padres e suas famílias. Trad. Thereza Kipnis. São Paulo: EDUSP EDHART, 1977. 
KUBLER, R. E. A Roda da Vida: Memória do Viver e do Morrer. São Paulo: Sextante, 1998.

KUBLER, R. E. A morte: um amanhecer. São Paulo: Pensamento-Cultrix, 1999.

KUBLER, R. E. O Túnel e a Luz: reflexões essenciais sobre a vida e a morte. Campinas: Verus, 2003.

KOVÁCS, M. J. Educação para a morte: temas e reflexões. 2.ed. São Paulo: Casa do Psicólogo, 2008. 224 p.

KRUG, E. G.; Et al. Relatório Mundial de Violência e Saúde. Genebra: Organização Mundial de Saúde, 2002. Disponível em: <https://www.opas.org.br/wp-content/uploads/2015/09/relatorio-mundial-violencia-saude.pdf >. Acesso em: 17 de jul. 2017.

PAUlA, B. de. Pedaços de nós: luto, aconselhamento pastoral e esperança. São Bernardo do Campo: Aste: Editeo, 2011. 231 p.

SILVA, L. F. da. Fraternidade e superação da violência. VIDA PASTORAL Temas sociais: a questão da violência, São Paulo, ano 59, n. 59, p. 3-12, jan./ fev. 2018. Disponível em: <http://www.vidapastoral.com.br/wp-content/uploads/2017/12/VIDA_PASTORAL_319.pdf 〉. Acesso em: 17 de jul. 2017.

SIQUEIRA, T. M. Tirando o pó das palavras: história e teologia de palavras e expressões bíblicas. São Paulo: Cedro, 2005. 174 p.

TUTU, D. O livro do Perdão. Rio de Janeiro: Valentina, 2016.

Recebido: 17/07/2017

Received: 07/17/2017

Aprovado: 15/11/2017

Approved: 11/15/2017 